\title{
Identifying Contradictions in Science Education Activity Using the Change Laboratory Methodology
}

\author{
Athina Christina Kornelaki ${ }^{1, *}$ \& Katerina Plakitsi ${ }^{1}$ \\ ${ }^{1}$ Department of Preschool Education, University of Ioannina, Greece \\ *Correspondence: Department of Preschool Education, University of Ioannina, Greece. Tel: 30-698-415-1653. \\ E-mail: athinako91@yahoo.com
}

Received: January 28, 2018

Accepted: March 16, 2018 Online Published: March 30, 2018

doi:10.5430/wje.v8n2p27

URL: https://doi.org/10.5430/wje.v8n2p27

\begin{abstract}
The study is based on an implementation of the basic steps of the Change Laboratory methodology (Engeström, Virkkunen, Helle, Pihlaja \& Poikela, 1996) at the University of Ioannina. It was derived by a discussion with master's students during a course about science education curricula in pre-school and primary education and their effectiveness in the current educational system. Students' engagement in Science Education is a multifaceted and complex process. Under a socio-cultural approach it constitutes an activity system which consists of several elements and as a whole, is interconnected and interacting with more activity systems which interfere in the process. The element that connects all the above systems is the shared object which in the case we are studding is the enhancement of teachers' confidence in teaching science education. The developmental work research methodology (Virkkunen \& Newnham, 2013; Engestrom, 2015) was chosen in order the participants to reflect on the current activity, to identify the contradictions of the activity and propose solutions forming a new model. Within this implementation Engestrom's triangular model of the Activity system (2001) is deployed and qualitative research methods are applied to analyze the content of the CL sessions occurred among participants. The findings of this study attempt to examine the challenges of the participating teachers in teaching science education and how their confidence can be enhanced and furthermore, the CL methodology as a tool in professional development.
\end{abstract}

Keywords: science education, change laboratory, contradictions, activity

\section{Introduction}

This study is based on an implementation of the basic steps of the Change Laboratory methodology (Engeström et al., 1996) at the University of Ioannina. It was derived by a discussion with master's students during a course about science education curricula in pre-school and primary education and their effectiveness in the current educational system. Students' engagement is a multifaceted and complex process. Under a socio-cultural approach it constitutes an activity system which consists of several elements and as a whole, is interconnected and interacting with more activity systems which interfere in the process. The element that connects all the above systems is the shared object which in our case is the enhancement of teachers' confidence in teaching science education. The developmental work research methodology (Virkkunen \& Newnham, 2013; Engestrom, 2015) was chosen in order the participants to reflect on the current activity, to identify the contradictions of the activity and propose solutions forming a new model.

In the past, science education was considered a part of an elitist science and responded to learning needs of only one percent of the population by offering a set of concepts and theories detached from their socio-cultural context (Plakitsi, 2012; Kaptan \& Timurlenk, 2012). Children's development of creative and critical thinking, the ability to formulate inquisitive questions, problem solving, argumentation and other scientific skills that will build a modern active citizen that is scientifically and technologically literate are suggested to begin already in early years of education. The above dimensions shall be considered when configuring education according to UNESCO and the 2030 Agenda for Sustainable Development and especially the fourth goal about quality in education. Children in a safe and stimulus rich environment explore with senses, create ideas and structure knowledge. As they grow, they lead to more complex forms of interaction with peers and adults that affect their linguistic and cognitive abilities. 
Until this goal is met, of configuring education and specifically science education based on societal needs, there are lots of steps to be made in everyday activity. Nowadays, efforts are being reported in this field (Raikou, Karalis \& Ravanis, 2017; Ravanis, 2017; Roth, Goulart \& Plakitsi, 2013; Plakitsi, 2013; Braund \& Reiss, 2007) which attempt to adapt a socio-cultural perspective in science education considering that children spend two thirds of their lives outside the school environment (Braund \& Reiss, 2007). Furthermore, another critical dimension of science education is as Kaptan and Timurlenk described (2012),

"...its dogmatic, authoritarian and extended science education where students must accept what they are told as unequivocal, uncontested and unquestioned".

Consequently, the focus is turned to teachers who possess a catalytic role in educational process. Only when they feel confident and well-trained, they will be able to consider all the above as tools in their hands in order to make science education sufficient and appealing to students. Therefore, meaningful teachers' training and their professional development as well as the enhancement of teachers' confidence in science education, is recommended to be seen as a priority. Thus, the change laboratory methodology is implemented in this study as a potential tool in teachers' training.

\section{Method}

The Change Laboratory is a formative intervention method introduced by Engestrom (1996). It is based on the expansive learning cycle (Engestrom, 2015) and it is carried out between professionals of an activity who share common goals and a small group of researchers. The aim of the change laboratory is the transformation of the current activity towards the development of the human activity. With the CL method change is pursued when an emerging need is arisen at a workplace (Virkkunen \& Newnham, 2013). It is organized into intensive sessions between the practitioners and the researchers and through these sessions the activity system is analysed from the past till present in order the challenges to be identified and a new form of the activity to be designed creating a new model.

The whole procedure is sub-served by the $3 \times 3$ surfaces which relate to the Mirror (reflection on the activity), Model/Vision (model of the activity and its systemic structure) and the Ideas/Tools (synthesis of the activity), that are used by the practitioners to write down the activity's attributes and insights for further development emerged by the inquiry of the above. The process of the Change Laboratory is supported by the phases of the expansive learning cycle: Charting the situation; Analysing the situation; Creating a new model; Concretising and testing the model; Implementing the new model; Spreading and consolidating (Virkkunen \& Newnham, 2013).

Engestrom's triangular model of the Activity system (1999) is deployed to examine the contradictions and to form the model of the activity. Engestrom proposes the organization of an activity system (extended triangle of activity theory) with the elements of subject (individuals or organization), tools (physical and/or conceptual), purpose (goal), rules (obvious and/or implied shaped by the subjects), community (where tool-mediated activity takes place) and division of labor (the way community members distribute responsibilities). According to Engestrom (1987), four levels of contradictions are identified within the human activity system:

- Primary inner contradictions refer to the double nature within each constituent component of the central activity and they are depicted within a corner of the triangular activity system's model.

- Secondary contradictions are located between the constituents of the central activity thus, between the corners of the triangular activity system's model.

- Tertiary contradictions are observed between the object/motive of the dominant form of the central activity and the object/motive of a culturally more advanced form of the central activity.

- Finally, quaternary contradictions appear between the central activity and its neighbor activities (Engestrom, 1987).

This paper is an attempt to examine the challenges of the participating teachers in teaching science education identifying contradictions within the activity systems and how teachers' confidence can be enhanced applying the CL methodology as a tool in teachers' training.

\subsection{Preparing the Change Laboratory}

Implementing a literature review more topics of discussion and research were triggered and the results of the desk research constituted the initial mirror data. In a lot of developing countries, including Greece, science education 
seems to be in crisis (Braund \& Reiss, 2007). This is also proved by Greek performance in the Program for International Student Assessment's tests (PISA). Osborne and Dillion (2008) suggest researching the phenomenon under a cultural perspective and "...beyond science education itself...". In most of the literature researchers identify the issue of students' disengagement in STEM education in secondary school. The source of the problem may already be identified in early grades, for which there is scarce literature (Plakitsi, 2012; Roth et al., 2013; Ravanis, Koliopoulos \& Boilevin, 2008; Fleer, 2006; Fleer, 2009) although a developing interest is located recently in the field (Ravanis, 2017). On the one hand, there are studies that prove that teachers' difficulty in transmitting scientific knowledge and information is an important factor in the reluctance of early grades' teachers to teach science (Watters 2001; Kallery \& Psillos, 2001; Yilmaz-Tuzun, 2008). On the other, there are studies which suggest the integration of science education in early grades (Tu 2006; Fleer, 2009; Greek Ministry of Education, 2011; Roth et al., 2013) as a natural consequence of children's innate curiosity about the world around them and their eager to discover and explore.

By literature review the aforementioned conflict showed up and master's students altogether expressed their willingness and interest to further investigate this issue. The change laboratory was organized in weekly 3-hour sessions. The participants were consisted of three female pre-schools and three female primary in service and potential teachers. The range of the participants' age was between 23 to 37 years old. The research group was consisted of a University professor in the field of Science Education and an assistant researcher who was a $\mathrm{PhD}$ student whose thesis was targeted on the same field. Since the participants were few and some of them with only a little didactical experience, more teachers as well as a school principal and a school counsellor were employed through their interviews in order to acquire a more holistic view of the topic.

Table 1. The Direct and Indirect Participants of the Change Laboratory Methodology Derived from NVivo Software

\begin{tabular}{cccc}
\hline & A: Name & B: Sex & C: Occupation \\
\hline 1: CL participants & Not Applicable & Not Applicable & Not Applicable \\
2: E.. & Eva & female & Pre-school teacher \\
3: G. & Glykeria & female & Primary teacher \\
4: L. & Lina & female & Pre-school teacher \\
5: T. & Thalia & female & Primary teacher \\
6: V. & Vasia & female & Primary teacher \\
7: N. & Natase & female & Primary teacher \\
8: MD interviewees & Not Applicable & Not Applicable & Not Applicable \\
9: School counselor & Unassigned & male & School counselor \\
10: School principal & Unassigned & male & School principal \\
11: Teacher 1 & Unassigned & male & Primary teacher \\
12: Teacher 2 & Unassigned & female & Primary teacher \\
13: Teacher 3 & Unassigned & female & Primary teacher \\
14: Teacher 4 & Unassigned & male & Primary teacher \\
15: Teacher 5 & Unassigned & male & Primary teacher \\
16: Researcher & Unassigned & female & researcher \\
\hline
\end{tabular}

All subjects who were involved in the Change Laboratory either in person or via their interviews are listed in the table above. The subjects indicated with the initial letters of their names are those who participated intensively in the change laboratory sessions while those whose names are not indicated are the people who were interviewed anonymously for the research needs.

\subsection{Gathering Mirror Data}

The mirror data was gathered by the researchers in collaboration with the participants. Overall, besides the literature review, interviews given by the teachers, school principal and counsellor, students' interviews and interviews from parents were collected. Prior to the interviews taken, researchers and participants considered the topics mirror data would be acquired about. 
Table 2. The Topics According to Which the Interviews Were Carried Out

\begin{tabular}{lll}
\hline Subject & & \multicolumn{1}{c}{ Topics } \\
\hline School counsellor & - & Teachers' strengths and weaknesses \\
& - & Tools used in science education \\
School principal & - & How challenges are arranged \\
& - & Teachers' strengths and weaknesses \\
Teachers & - & Tools used in science education \\
& - & How challenges are arranged \\
Students & - & Teachers' equipment \\
& - & Tools used in science education \\
Parents & - & Teachers' confidence on teaching science education \\
& - & Subject preference \\
& - & Likes and dislikes about science education \\
& - & Subject's tasks in class \\
& & - Subject's importance \\
& &
\end{tabular}

The above table (2) of topics was emerged, and the interview protocols were designed accordingly. All the interviews were recorded or videotaped and finally transcribed. These interviews were analysed and discussed during the sessions which were also videotaped so the researchers-interventionists could analyse them after the sessions. The mirror data was limited to the interviews as well as participants' views and assessments due to the limited time and constrains of having video clips of actual teaching practices. All the data gathered was analysed with a qualitative data analysis software, NVivo 9. NVivo helps when organizing and analysing unstructured data because it supports working with rich text-based information where deep levels of analysis on small or large volumes of data are required.

\subsection{The Sequence of Change Laboratory Sessions}

The Change Laboratory was offered in the second semester of the 2016 academic year and it was a complementary workshop series to the course offered by the professor. The sessions had to be organized during that semester so, the time was limited and not all the phases of the process were applied. Specifically, the three first phases were carried out within six intensive weekly sessions.

Table 3. The Session Time Use According to Preliminary Design of the Change Laboratory

\begin{tabular}{|c|c|c|}
\hline Session & Hours & Content \\
\hline 1 & 3 & $\begin{array}{l}\text { Introducing Change Laboratory methodology and the way of working, interview each } \\
\text { other, discussion on stimuli provided. }\end{array}$ \\
\hline 2 & 3 & $\begin{array}{l}\text { Analyzing, thinking and discussing mirror data, charting the current activity and forming } \\
\text { research questions for further investigation. }\end{array}$ \\
\hline 3 & 3 & $\begin{array}{l}\text { Analyzing changes and charting the development of the activity, identifying } \\
\text { contradictions. }\end{array}$ \\
\hline 4 & 3 & $\begin{array}{l}\text { Modeling the activity and its contradictions by studding the network of the activity } \\
\text { systems emerge, searching for ideas and solutions }\end{array}$ \\
\hline 5 & 3 & Modeling the new form of activity, anticipating disturbances \\
\hline 6 & 3 & Finalizing the new tool. \\
\hline
\end{tabular}

The preliminary idea of the use of the session time is presented in the table 3 above. In this paper mostly the second phase of the Change Laboratory process will be presented, the analyzing of the situation. 


\section{Results}

\subsection{Challenges in Science Education Teaching}

Interviews' analysis was occurred by the researcher and CL participants during the sessions. Going through the interviews and listening to recorded excerpts, participants were discussing and keeping notes on the Mirror/Present surface. The aim of doing the analysis in collaboration with the participants was to identify the disturbances and inner contradictions of the activity. Under a socio-cultural perspective where activity system is considered dynamic, the allocation of the contradictions and disturbances constitute the most important step towards transformation and change of the activity (Engestrom, 2001, Roth, 2004).

Studding the mirror data and videotaped sessions, it was seen that a very big part of the interviews and the discussion among participants concerned the challenges teachers face when teaching science education given the fact that there are 72 references about this topic according to the data organized in NVivo software. In the Matrix Coding Query below the challenges reported by the interviewees are presented in relation to the person who introduced each one of them.

Challenges - Results Preview

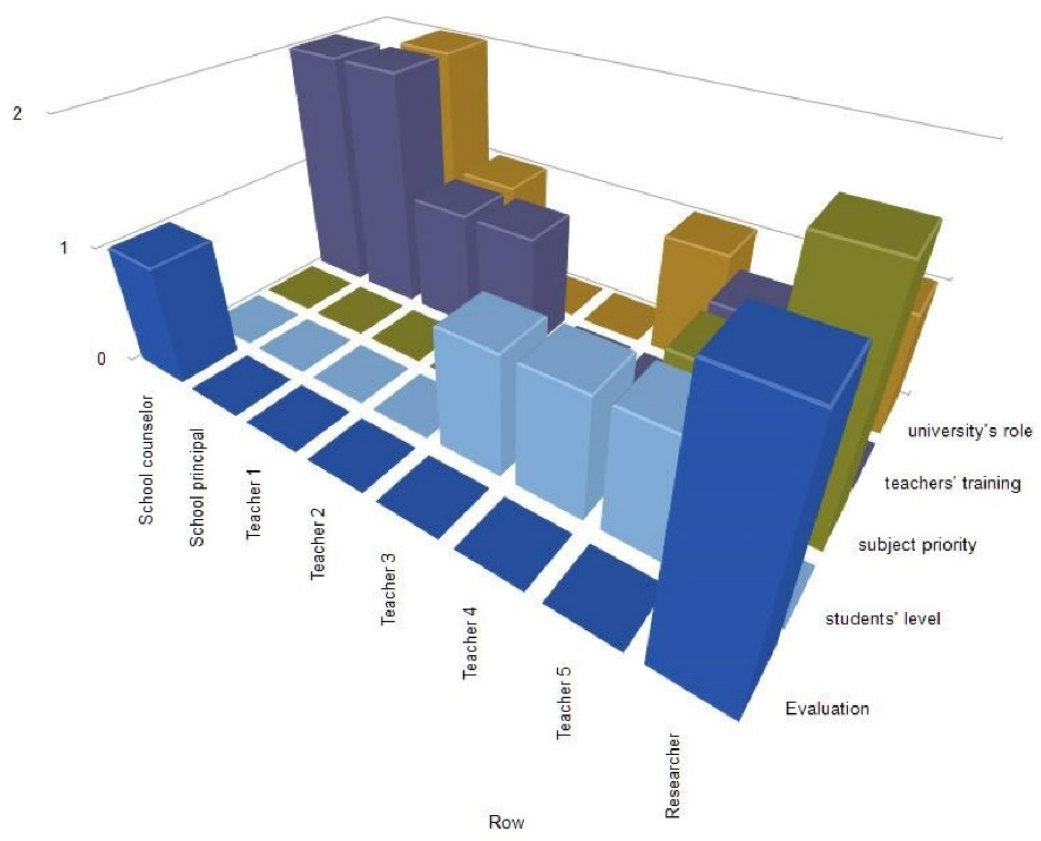

Figure 1. NVivo Matrix Coding Query of the Challenges Emerged by the Interviewees

Visualizing the challenges reported in relation to the number of the interviewees' references (Figure 2) we can easily deduce that one of the challenges for teachers is students' level. 
Nodes compared by number of iterms coded

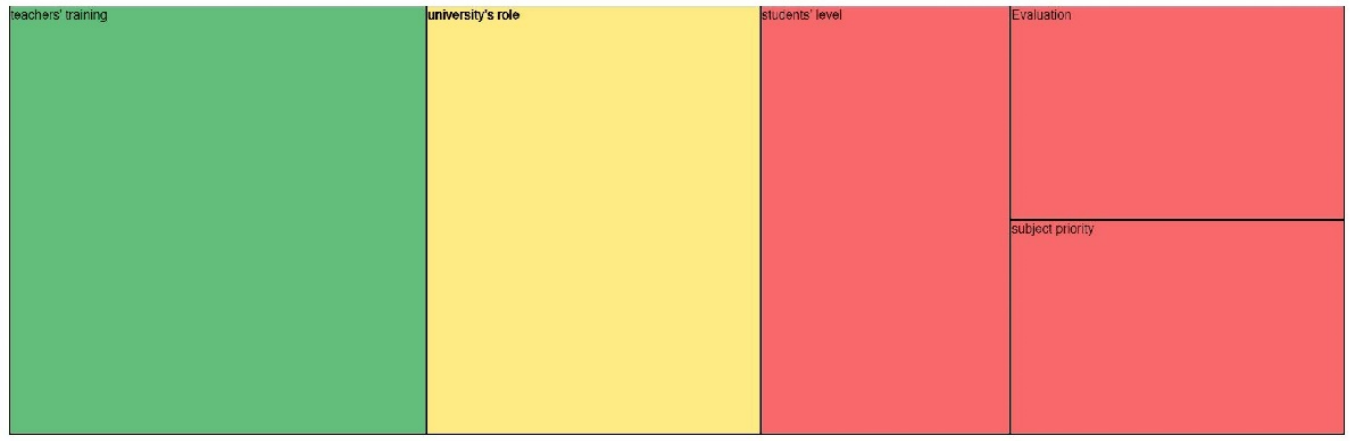

Figure 2. Tree Map of the Challenges Relate to the References Gathered in NVivo

\subsubsection{Challenge 1: Students' Level}

According to the transcribed interviews, teachers consider students' level and prior knowledge a very important factor that influence teaching science education (23 references).

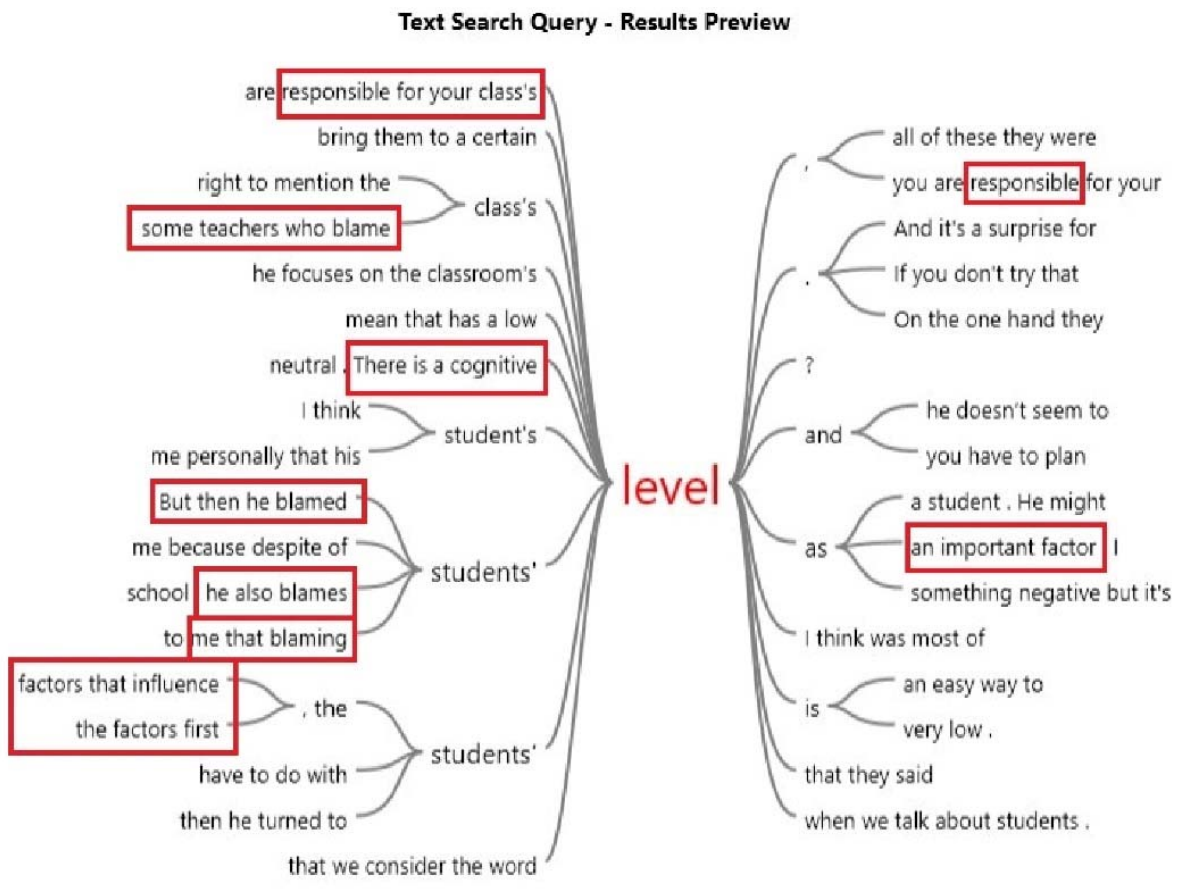

Figure 3. NVivo Text Search Query of the Word Level

The use of the text search query implies the correlation of the word's interactions with other concepts. This process allows us to search for words or phrases in sources of the text that has been analysed and to look for its interaction with other concepts as well as its dynamics in the activity system. In figure 3, exported from NVivo software, the main connections of the word level and its controversial role are depicted.

The participant's views on the topic while listening the first interview led to a contradiction. One of the participants (T.) started conveying interviewee's words when two participants (N. \& G.) agreed on the statement reasoning their view. The discussion became more intense when participant E. argued that students' level shouldn't be a problem in designing science education activities. 
T.: This teacher mentions the complexity of teaching science education and the different factors from which is depended such as students' level.

N.: Yes, you adapt the designed activities according to your students. There is a chance that they don't carry appropriate stimuli from their family. Maybe you have to start from low and do more things in order to make your students able to participate in certain activities that you probably could do with other students from the very beginning.

G.: You can't do an activity you would do with an advanced class because students wouldn't be able to correspond to it.

E.: I disagree. Since our initial target is not the cognitive development itself but to encourage students discover and learn by discover, activities should not focus on knowledge that much but on the process of students' learning. Therefore, you should be able to do the same activities to all the students of the same age and the extent of the activities could vary.

G.: But if they don't understand the content of the activity how they could possibly follow cognitively and mentally and participate ...

Another participant (L.) interfered and quite irritated argued that students' level is in most cases an excuse that teachers use when they want to justify their weakness in teaching science.

L.: ... this part reminds me of some teachers who blame class's level. On the one hand they state that they are not well trained and so on, they blame the government, the system and when it comes to the classroom they also blame students; it's convenient for them.

Then participant V. disturbed by the previous speaker's accusation about teachers, shared her own experience from when she was doing her practice as an undergraduate student.

$V$.: Can I note something about that? Because I've been in a school which is not considered very good and I had a class which truly... if we don't have a great experience with what a difficult class mean we cannot judge whether the teacher blames for no reason the students, me for example, I was in a class wondering how that teacher could manage those students, you cannot even imagine the situations and the incidents I came across in the classroom. We may have a certain idea of how a class is under a normal context but there are some very rough and serious situations going on in some classes. For example, if the teacher of the interview faces a similar situation in his class he has the right to mention the class's level as an important factor. I don't really believe that he said that to throw the blame elsewhere but maybe he has a non-manageable class.

After V.'s interference the discussion calmed down and the speakers agreed that there are different kinds of teachers and not all of them are the same. The emergence of V.'s personal sense in the object (Sannino, 2008) led participants to a compromise and to an acknowledgement about teachers' values.

The same topic came up again during the session when another teacher in an interview mentioned as a factor of influence in science education, students' prior knowledge and perceptions. The discussion was tense and again V. interfered to explain her perception about what the interviewee might meant.

L.: She approached better the issue than the previous giving the responsibility to teachers and not to students talking about prior perceptions.

E.: It's correct. More than the others.

L.: Much more because when you talk about prior knowledge you think I'm going to search for it and I will build on it. If I believe that it's students' fault, then I whether work or not.

$V .:$ I don't think that the others meant that it's students' fault. They just mentioned students as a factor that plays a part in the process.

Then E. opposed suggesting again that teachers shouldn't be looking for prior knowledge at all.

E.: But it's different when we talk about prior knowledge because a student who doesn't have rich prior background doesn't necessarily mean that has a low level as a student. He might be very good at language or to other subjects why should we focus on prior knowledge?

And $\mathrm{V}$. in a critical tone posed an objection about the terminology use.

$V .:$ I think that we consider the word level as something negative but it's actually neutral. There is a cognitive level when we talk about students. Whether you recognize it or not, there is and it's measurable. 
According to the above excerpts, there are teachers who consider students' prior knowledge and search for ways to build on them, there are teachers who use it as an excuse to alleviate their workload and finally there are teachers who don't believe that students' prior knowledge limits the topics and activities a teacher wishes to do in class. All participants agree that handling student's level depends on the teacher and his/her values. The above disputation is a visible manifestation of an inner contradiction within the constituent component of instruments and values in the central activity. It is attributed by its multifaceted nature and it constitutes a primary contradiction according to the four levels of contradictions within the human activity system (Engestrom, 1987). The aforementioned contradiction was taken into account and exploited by the participants in forming the new model phase.

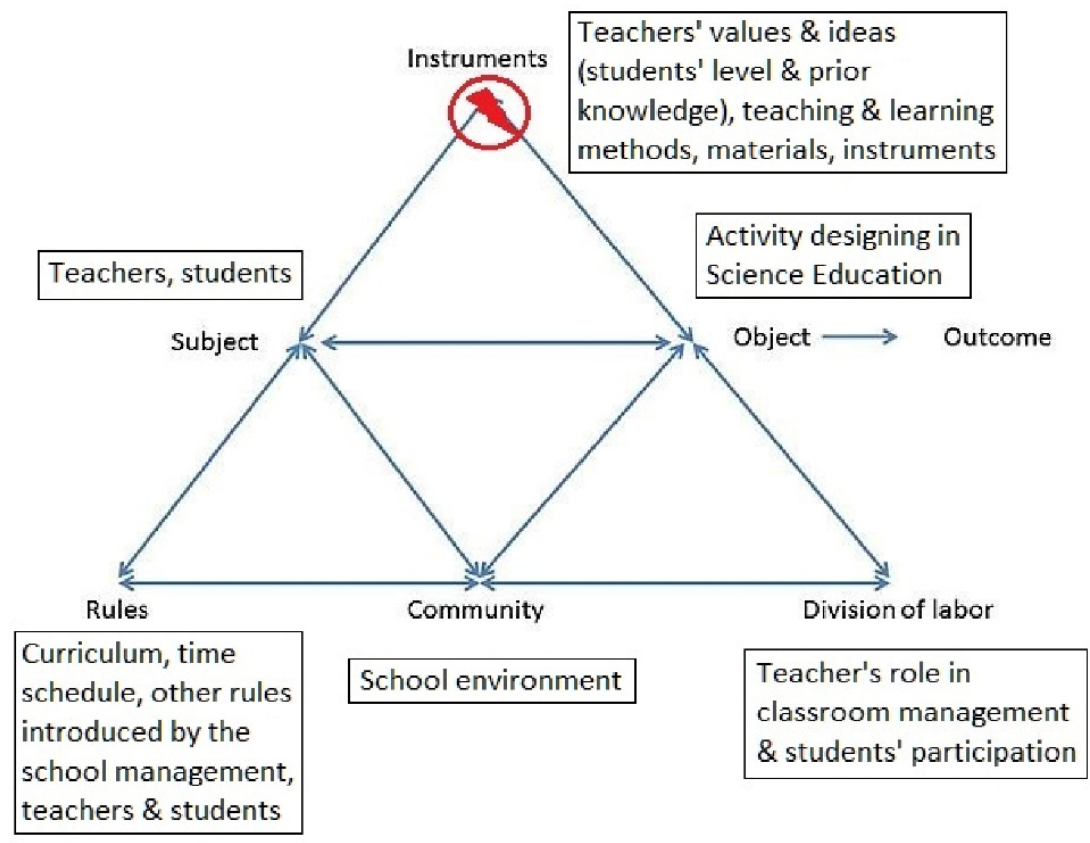

Figure 4. Primary Contradiction Relating to the Component Instruments in the Activity System

\subsubsection{Challenge 2: University's Role}

Another contradiction emerged from the interviews was related to the University's role in teachers' readiness to undertake a class and teach science education after graduation. Participant G. wanted to make sure that the reference about the university was written on the Mirror/Present surface under the challenges.

G.: Did we write down the University's syllabus?

Participant $\mathrm{N}$. then expressed her opinion about university's role in preparing future teachers and the researcher asked for more information regarding the amount of time dedicated in science education during the university studies to become a primary teacher.

N.: At the university though, you just get the idea you cannot get everything in detail, it's impossible.

Researcher: It's the same with the students who study to become primary teachers isn't it? For example, how much time is dedicated in science?

The researcher's question triggered a discussion about teachers' readiness after graduation and V. shared an experience and the agony she felt as a teacher during her practice. It was proved that the discussion that followed was very fruitful since it led to proposals which were then written on Ideas/Tools surface.

V.: Very little. Personally, I believe that there should be some changes in the university syllabus, at least regarding primary teachers. You are not taught didactics of science or mathematics, it's something else, nothing like didactics. I remember myself feeling very very awkward when the teacher was leaving the classroom and I had to undertake. You are just standing there, and you must think from the beginning what you can do in class, because you try to recall the courses you have attended, and they are not helpful. You are didactical inadequate. 
Researcher: What would help you more?

V.: To focus more on didactics. Some exemplary teachings to be offered.

G.: Yes, this would help a lot. Mostly.

V.: Generally, I think that the university department is far from the school reality. We do so many courses on linguistic for example, which is very important, I can't disagree with that, but didactics is weakened at the university.

E.: On the other hand, the university aims to give us all the knowledge and then we should transform it into practice.

N.: Ok, but after you have learned so many things, in the end, there's nothing left. You don't remember any of them.

G.: And when you are in the classroom they tell you now teach the students, even though you were never taught how to teach. They have given you only a little of each subject, a little physics, a little math...

N.: The subjects which need didactics should be taught differently and exemplary teachings would help a lot to that direction.

V., G.: Yes, the exemplary teachings are absent and essential.

In a different $\mathrm{CL}$ session university's role once again came up as a topic of discussion among participants. Motivated by an interviewee's suggestion having different specialties of teachers in primary education, they were very preoccupied with the fact that acquiring the subject-relevant knowledge doesn't necessarily make you effective in teaching.

T.: He suggests graduating from the university with a subject specialty. To attend university like everybody does now, but to have some more courses on a specific area, physics, mathematics, literature.

V.: This is something already happening in teachers' department but honestly it doesn't really give much to students because the courses are very theoretical, and they don't really help learning how to teach practically.

E.: On this case we can refer to high school teachers who can be for example physicians with extra training in science education and even though they possess the concepts very well they are not necessarily effective when teaching those concepts, so it's not enough to hold the concepts profoundly.

By this discussion prominence to the gap between theory and praxis was given regarding the university curriculum.

G.: For us, that we are not physicians or chemists, or mathematicians and we will be in the class practice is very important. You have to know the theory for sure but it's not enough...

Finally, the students' fragility in the ages of pre- and primary school was pointed out as a motivation for teachers to try harder engaging students in science education. When students adopt a stance on a subject is very difficult to reform it in high school.

L.: I also believe that practice, the teaching part is very important because when students go to high school and they have teachers with specific subjects who can give them the knowledge, but students have already loved or hated physics from primary school...

N.: Yes, the bond you have with younger students is different from the one in high school. Until primary school students are in a very tender age.

In the above excerpts a fourth level, quaternary, contradiction is emerged between the central activity and its neighbor activity system (Engestrom, 1987) as it is presented in Figure 5 below. Participants expressed their agony as they experienced it when they were asked to undertake a classroom and teach science education in their early years or during their practice in schools as undergraduate students. When they were in the classroom they felt obliged to correspond to their duty while at the same time they felt unprepared and poorly trained. This situation is rather inconsistent since on the one hand teachers are involved in the activity of teaching in classroom while on the other, university undertakes the role of training prospective teachers and accordingly ensures their readiness to teach in class which in this case is considered inadequate. 


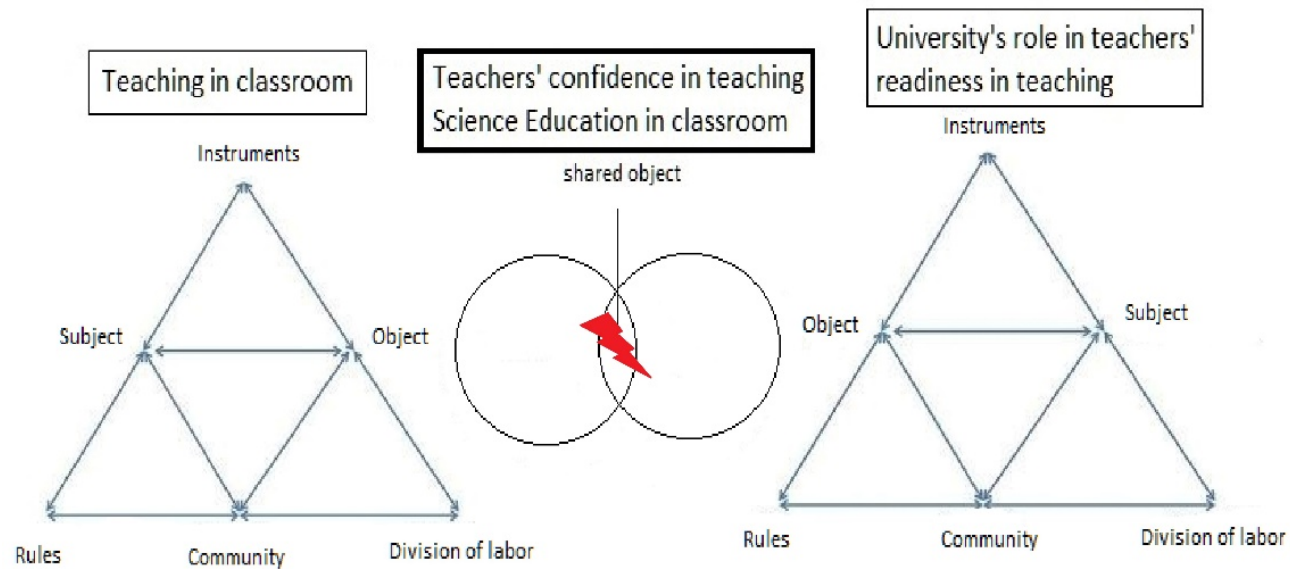

Figure 5. Quaternary Contradiction between Neighbor Activity Systems Regarding the Shared Object

Within this discussion participants altogether expressed the need for some courses' enhancement in university syllabuses with exemplary teachings in class and longer practices in schools before graduation. These ideas were listed on the Ideas/Tools surface, under the solutions proposed by the CL participants.

\subsubsection{Challenge 3: Subject Priority}

Another challenge introduced by an interviewee was that teachers decide which subjects are taught in priority. Consequently, there are subjects, such as science education which are not taught as frequently as the school program suggests.

Researcher: I was impressed when the teacher said that it depends on how much the teacher gives priority to a course.

L.: Yes, it happens, there are teachers who focus mostly on language.

N.: Yes, if they like language very much means they are good at it. Alongside, there are teachers who hate math and they are not good enough. If you like a course you definitely convince and inspire your students more.

G.: Definitely

E.: Additionally, you are better at it since you get it better, otherwise you just try to fill your own gap.

G.: And when you suppose to have an hour language and two mathematics for example, you will steal an hour from mathematics to have more time for language.

V., G.: Yes, it happens

N.: And students also like this and they want more.

L.: I know a teacher in first grade that teaches language while she is teaching mathematics. For example, when they learn addition or subtraction she emphasizes on writing the words addition and subtraction and copy the words and the mathematical problem from the blackboard.

A contradiction derived from the above discussion was located between two activity system's components. On the one hand there is the school curriculum and time schedule which relate to the school's rules while on the other there are teachers' norms and values about the different subjects and courses taught. The latter relates to the subjects of the activity, teachers in this case and more specifically with the instruments in which teachers' values and ideas about teaching and learning are implied. Thus, a secondary contradiction is resulted as presented in Figure 6. 


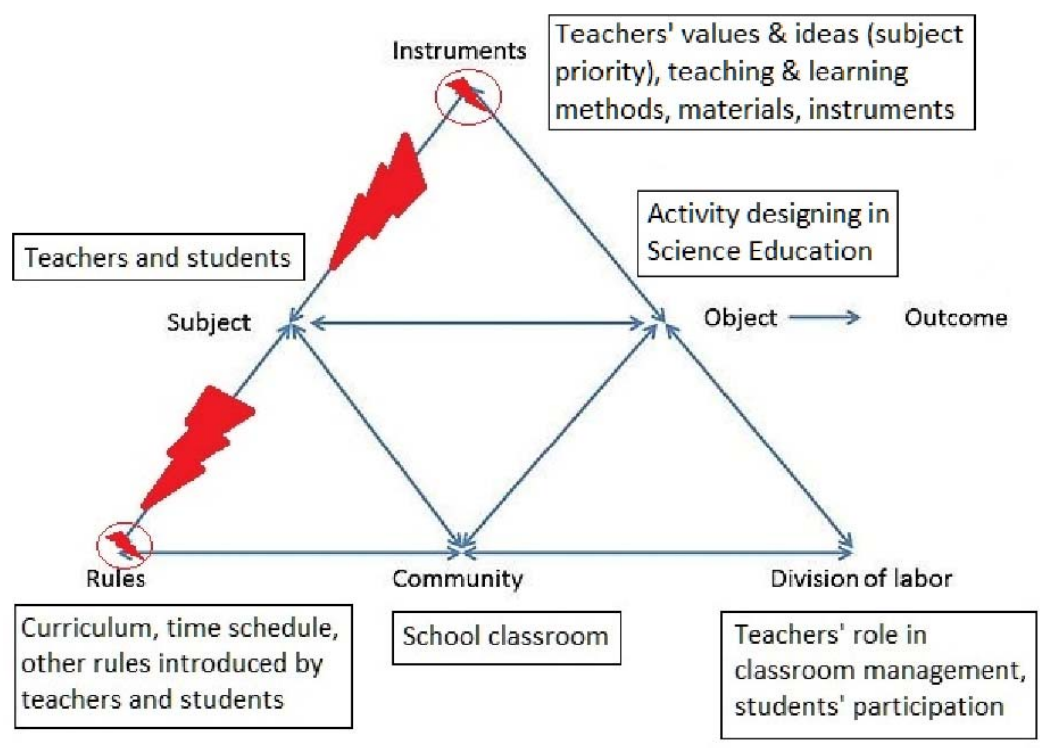

Figure 6. Secondary Contradiction Between the Components Rules \& Instruments of the Activity System

\subsubsection{Challenge 4: Teachers' Training}

The topic of teachers' training traverses the data gathered and analyzed for this study and it is quite repetitive with 21 different references according to NVivo software. It constitutes a twofold topic as it is presented as a challenge and a solution concurrently. Conducting a text search query in NVivo, topic's double nature is rather conspicuous.

\section{training - Results Preview}

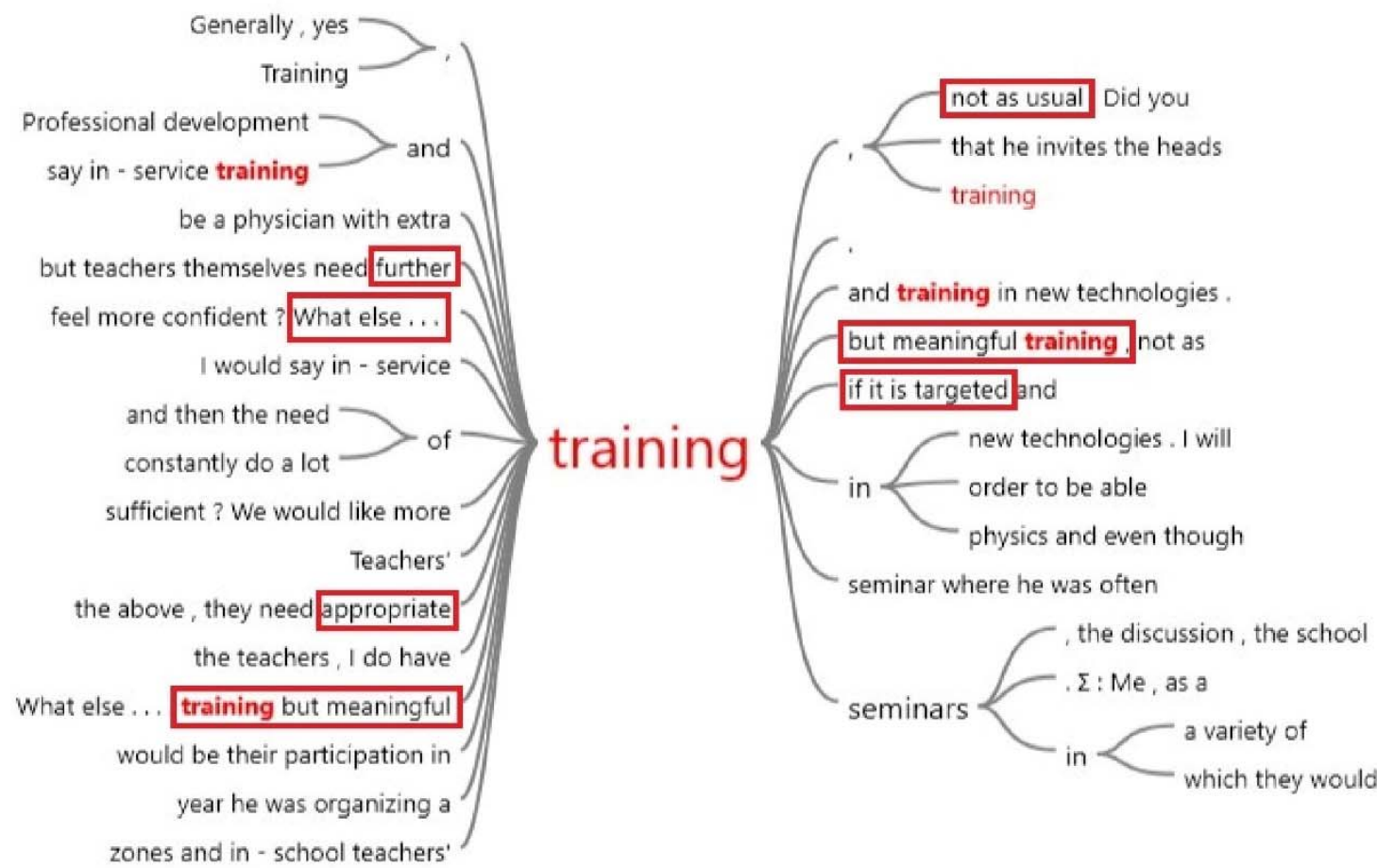

Figure 7. NVivo Text Search Query of the Word Training 
According to the Matrix Coding Query (Figure 1), five out of seven interviewees pointed out teachers' training as a challenge and denounced the way it is currently done judging from their personal experience. Despite their reproach, they proposed teachers' training as a useful tool for teachers' confidence enhancement regarding science education under certain conditions. They emphasized on training seminars which will be meaningful, targeted, appropriate and adapted into classroom reality. CL participants confirmed this case and N. shared a set of personal contradictory experiences from her current and former school counselor about training:

N.: ... at the school I am this year, they do a lot of things. I don't know if all school counselors do the same, but I believe so. I've heard from colleagues of mine that in Ioannina all school counselors are very active like ours. For example, almost every week our school counselor is at schools doing exemplary teachings, different schools each time, we can't see all the exemplary teachings, but she is active.

Researcher: He mentioned that with pre-school is different because there are more teachers in each region than in primary schools.

T.: It's also the time which is never enough.

N.: Still it's up to the school counselor. It's like we said about the teachers, it depends on whether he/she is willing to do things and if his/her teachers follow his/her events.

Researcher: So, that's why this interviewee mentioned the school counselors' evaluation.

N.: In my previous school our school counselor was not doing anything at all. Once or twice a year he was organizing a training seminar where he was showing a power point presentation and nothing else. Of course, not all of them are like that.

L.: No, they aren't. There is personal motivation, whether they are passionate about their job or at least they are doing their job or not.

N.: Yes, it's up to the person.

From the excerpt quoted and the interviewed teachers' points of view training's contradictory role is depicted. In an activity system where teachers' training in Science Education is the object, the training methods are located within the instruments component. Within the latter, trainers' values and ideas about teachers' training are also placed. Consequently, a primary contradiction is arisen within the constituent component of instruments in the current activity (Engestrom 2015) as it is demonstrated in Figure 8.

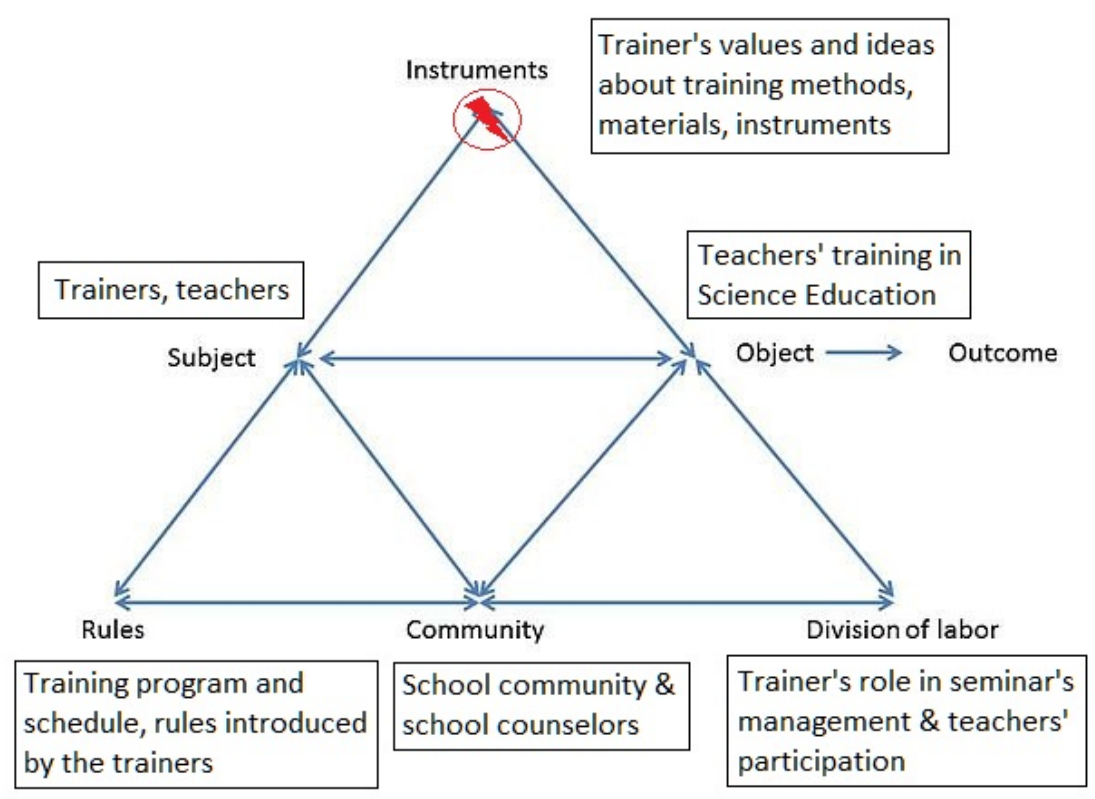

Figure 8. Primary Contradiction within the Component Instruments 


\subsubsection{Challenge 5: Evaluation}

In the same way, evaluation came up as a challenge as well as a solution from the school counselor's interview, in which he characteristically mentioned:

School counselor: It's up to them (teachers) and their ambitions, there is not a framework under which they are obliged to do certain things and to reach certain goals. There is not a framework for evaluation and self-reflection on how they should do their job. If there was, more teachers would do more things in their classes. Some teachers though, they already do even more than what you propose to them, they extend it and that's very positive.

Interviewer: What would you like to do furthermore?

School counselor: I would like to be close to every teacher separately and tell them you know what; I believe that you can improve this or that, you do very well this, but you should try more on that. Right now, I'm not in the position to do that.

Interviewer: So, what you need is further collaboration with teachers in person.

School counselor: Yes of course and in the same way teachers should evaluate and advice school counselor's work and vice versa always in a reflective way for self-improvement not judgmental.

Interviewer: Do you believe that it's possible to have that kind of evaluation?

School counselor: Of course, it is. Right now, we only do that when we face a problem in the class and students are already in danger... Of course, we can't wait until we face a problem we should do it all the time with all and for all teachers. We all have room for improvement.

After listening the interview, a discussion started among the CL participants who supported school counselor's view under the conditions he also suggested. In order evaluation to be efficient it is suggested to be implemented under a reflective and not judgmental way and free of political, economic and other interests.

N.: We should show using calendars, lap books, as he said, what we are doing in our classrooms, to keep all of the class's materials (paints, worksheets, photographs) everything and each one of us to have our portfolio with everything we did.

Researcher: Do you consider that as a bad thing?

L.: No, I think it's very right because it motivates you to work harder and better.

$V .:$ If evaluation is reflective and aims to teachers' improvement...

At this point $\mathrm{V}$. expressed her doubt and hesitation on whether the current educational system can be trustworthy implying that usually, when such frameworks are applied different kind of interests are emerged which influence and corrupt the process.

$V .:$ It's very good and important and every modern society needs evaluation because teachers can't just do what they want, but the thing is, who guarantees that evaluation will be implemented correctly and there won't be any constraints derived by political or other interests.

N.: It was very right said that they (school counselors) should be evaluated first of all.

V. again made a very interesting observation, regarding teachers' distance from the evaluation process. She points out that none of them mentioned evaluation as a challenge nor as a solution and she implied that this can be interpreted as their condemnation towards evaluation or as a random event.

$V .:$ But we didn't hear from any teacher about evaluation. It was not a topic during the previous interviews. We hear it for the first time from this school counselor. I don't say that this is necessarily connected with teachers' stance about evaluation and it's very important, but it was not mentioned so far. Only the school counselor brought it up.

The situation described above can be seen as a contradiction between two different activity systems. The one system is consisted of educational process's components and the other constitutes the educational system. In the first activity, evaluation is seen as a tool which mediates teachers' professional development and it is governed by the rules indicated by the educational system among other rules. The second activity system also utilizes evaluation as a tool for teachers' professional development but accepting V.'s implication about system's corruption, this system's rules may be influenced by certain interests which refer to rules component and influence both activity systems. In the latter case, we are talking about a quaternary contradiction (Figure 9). 


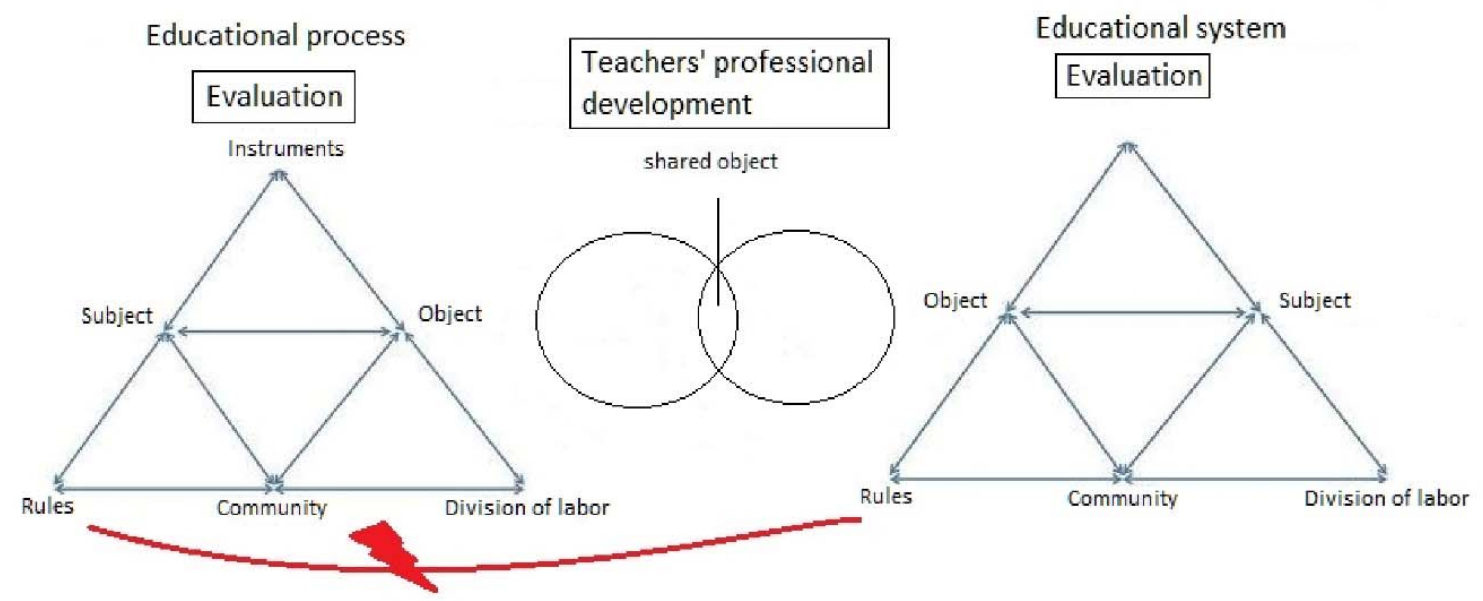

Figure 9. Quaternary Contradiction Between Neighbor Activity Systems Regarding the Rules

\subsection{Tools Used}

Running a text search query in NVivo, we can easily define the connections of the word tools within interviews and CL participants' references. An interesting point in a CL participants' discussion about the use of tools pertains the concepts modern and traditional as it is shown in the text search query below (Figure 10). The discussion was triggered by L.'s observation about the interviewees' answers on the question regarding the tools they use when teaching science education.

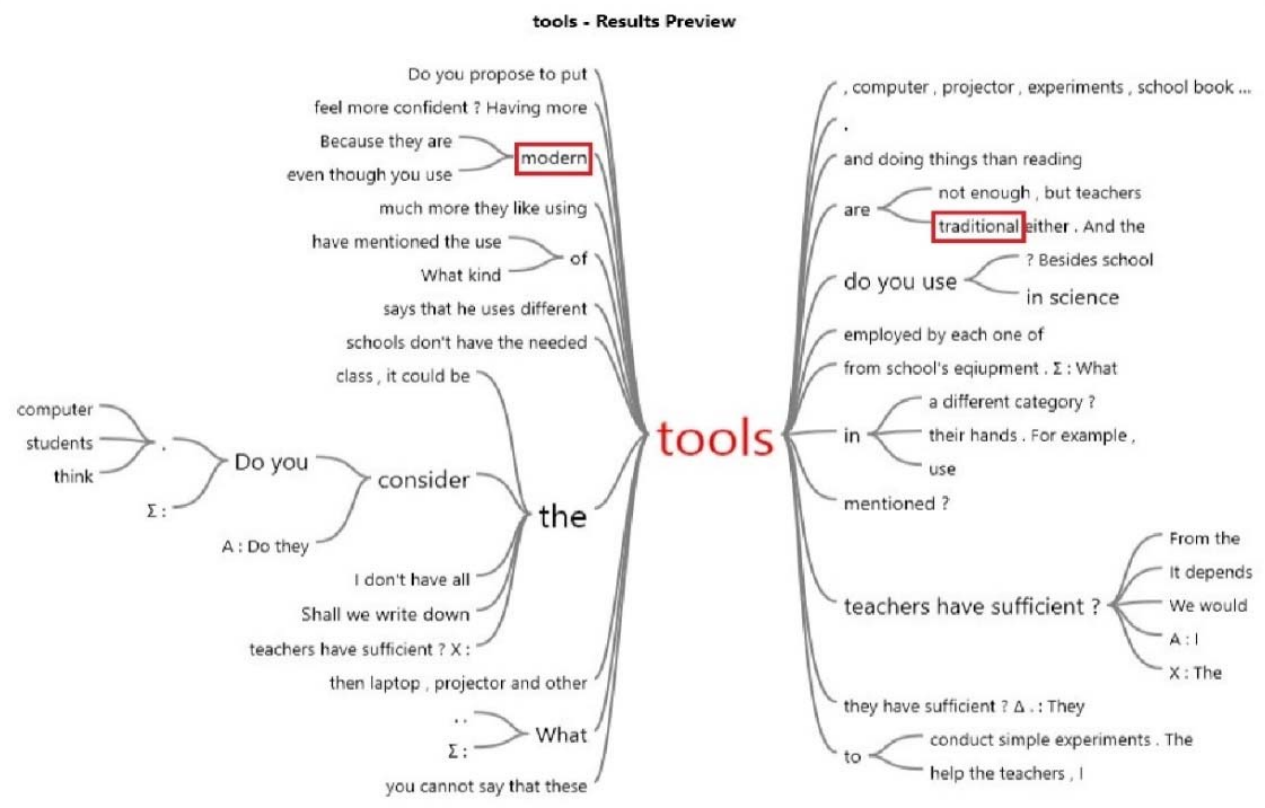

Figure 10. NVivo Text Search Query of the Word Tools

N.: Yes, a lot of them have mentioned the use of tools, computer, projector, experiments, school book...

L.: I can't understand why they focus so much on computer, projector, laptop and ICTs in class.

A debate then started on whether ICTs are necessary in teaching science education to young students as well as whether the use of ICTs which are considered modern tools can properly define teacher's teaching.

N.: Because they are modern tools. 
L. insisted on her opinion while G. opposed, suggesting that these ICTs are offering different tools which make the subject more interactive.

L.: Since we are talking about science education, I believe that you can do wonderful things without those.

G.: Yes, but there are interactive programs, software, experiments, simulations which you can use.

E.: I think that a complete set of activities needs all of them, so you can adopt a holistic view of a topic.

L.: And how did they teach physics 50 years ago? And they were doing it much better than today...

N. then introduced a concern about the tools' use.

N.: It's also important how you use a tool.

E.: I believe that new generations are advanced, and ICTs help significantly. To just see the sun with your eyes and understand some things only with your senses is not the same with the advantage of seeing something more by using a software.

L.: I'm talking about young students and they understand much better with modeling than seeing something on the computer because they just see it again and nothing more. When you are teaching through discover you let them touch, showing slides and doing a presentation is a traditional teaching method with nice pictures even though you use modern tools.

E.: But we are not talking about presentation.

After L.'s intervention an alteration in G.' stance was observed.

G.: Age matters though, because for students on sixth grade will be very impressive to see an experiment on a big screen than doing it with simple materials in class. It's different in kindergarten where students like exploring, touching, doing.

The discussion didn't lead to a conclusion about whether ICTs are appropriate in teaching science education in early grades, but it drew a different inference from the data. Participants culminated in the lowdown that the use of different tools doesn't define teachers' teaching method, but it can only be regarded as an attribute of the action. During another discussion it was noted:

N.: Yes, he said that he uses computer, a projector but it doesn't mean that he uses them collectively, but you cannot say that these tools are traditional either. And the last one who said that she goes outdoors they might go out to do something very specific such as to see a tree, it doesn't mean that she teaches by discover.

E.: Yes, the tools' use doesn't determine the way you teach.

T.: To see that, we may have needed to make more and clear questions in order to get an accurate image.

N.: And to observe.

Researcher: Either way, we are not here to judge teachers' methods, criticize or label them in a certain way.

N.: I am just saying that we cannot label them traditional nor modern because using some methods such as work in groups doesn't make you any of the above.

T.: We just have some indications that they use more modern theoretical framework.

V.: I also think that none of the above makes them traditional.

The latter excerpt can also be deemed as an inner contradiction, a primary contradiction within the component of instruments in the activity system (Figure 11). Some teachers may believe that using the so called modern tools makes their teaching method more modern. Some teachers though acknowledge that tools' use doesn't define their teaching method but the way of using them is a matter of interest. 


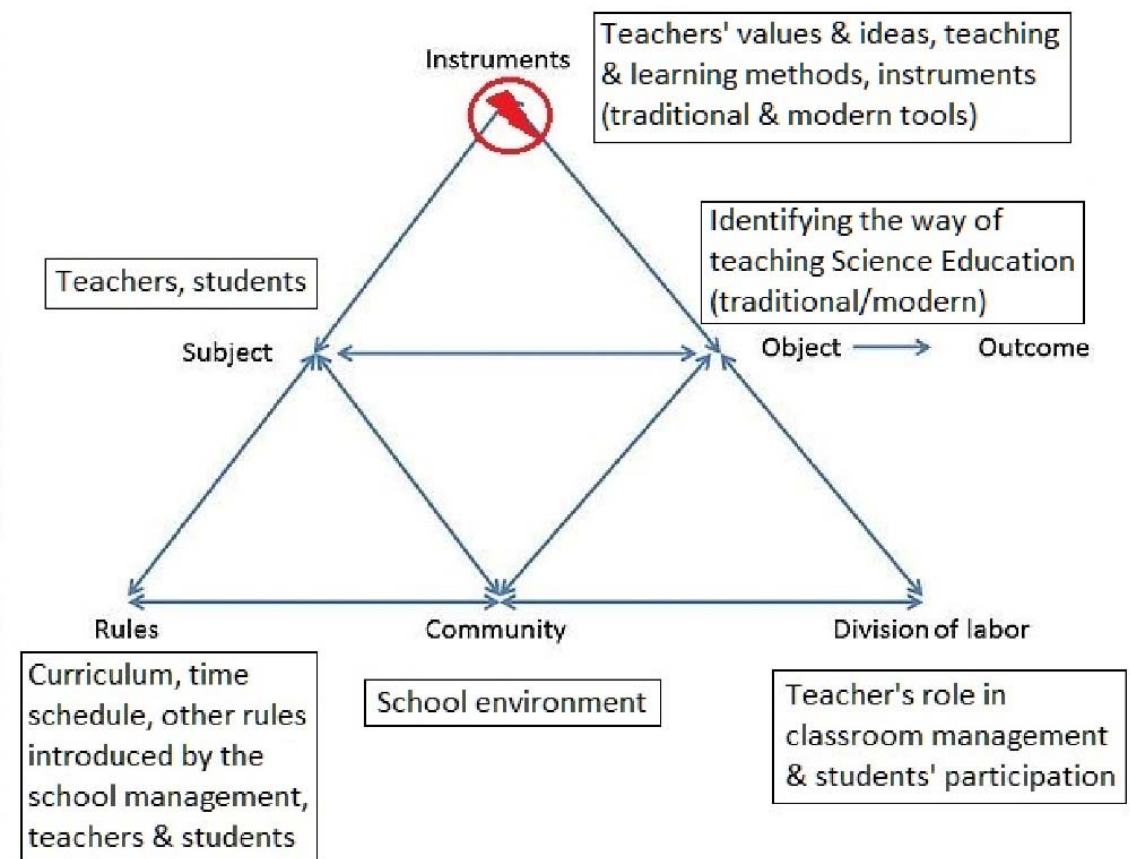

Figure 11. Primary Contradiction within the Component Instruments in the Activity System

\section{Discussion}

Activity is a dynamic system in which all the components according to Engestrom (1999) are constantly interacting with each other, within the system. Friction, as a result, may cause contradictions, which manifest themselves as "a misfit within elements, between them, between different activities, or between different developmental phases of a single activity" (Kuuti, 1996). Contradictions in CHAT possess a fundamental role since they are considered the sparkle from which the development of the human activity is achieved. The four levels of contradictions Engestrom (1987) exist in every collective activity system. Only when the contradictions are identified it is then feasible to "reconstruct the system in its concrete diversity and richness" (Foot \& Groleau, 2011) and thus be able to make inferences about the development of the system (Engeström, 1987). Therefore, acknowledging activity system's contradictions constitutes the head-start in the strangle of improvement. Regarding the activity we examine, teachers' every day challenges in teaching science education are the contradictions of the activity system and starting from them we can build on the future activity.

Table 4. The Contradictions Identified Overall

\begin{tabular}{|c|c|c|}
\hline No & Challenge & Level of contradiction \\
\hline 1 & Students' level & $\begin{array}{l}\text { Primary Contradiction relating to the component Instruments in the } \\
\text { activity system (Figure 4) }\end{array}$ \\
\hline 2 & University's role & $\begin{array}{l}\text { Quaternary Contradiction between neighbor activity systems regarding } \\
\text { the shared object (Figure 5) }\end{array}$ \\
\hline 3 & Subject's priority & $\begin{array}{l}\text { Secondary Contradiction between the components Rules \& Instruments } \\
\text { of the activity system (Figure } 6 \text { ) }\end{array}$ \\
\hline 4 & Teachers' training & Primary contradiction within the component Instruments (Figure 8) \\
\hline 5 & Evaluation & $\begin{array}{l}\text { Quaternary Contradiction between neighbor activity systems regarding } \\
\text { the rules (Figure 9) }\end{array}$ \\
\hline 6 & Tools used & $\begin{array}{l}\text { Primary contradiction within the component of instruments in the } \\
\text { activity system (Figure 11) }\end{array}$ \\
\hline
\end{tabular}


It seems that the steps of the change laboratory methodology supported efficiently the discussion among participants regarding teaching science education, which led to the identification of the activity system's contradictions. The challenges from which the latter emerged were student's level, university's role, subject's priority, teachers' training, evaluation and the tools used (table 4). The contradictions emerged in this study were located within and between (primary and secondary) the elements of the activity systems as well as between the main activity system and its neighbor activity systems (quaternary).

The open discussion and the interaction helped participants to reflect on the current activity, express their concerns and problems, propose solutions which were deployed for further development of the future activity and finally, charting the current situation. The examined activity system, which constitutes the initial goal of this study, is the enhancement of teachers' confidence in teaching science education. Towards it, the challenges of teaching science were identified as well as the factors that influence this activity and the solutions proposed by the participants. According to the implementation of the first two steps of the change laboratory's expansive learning cycle and the participation of the CL participants as well as the interviewees in the sessions, the following model represents the current situation of the activity system (Figure 12).

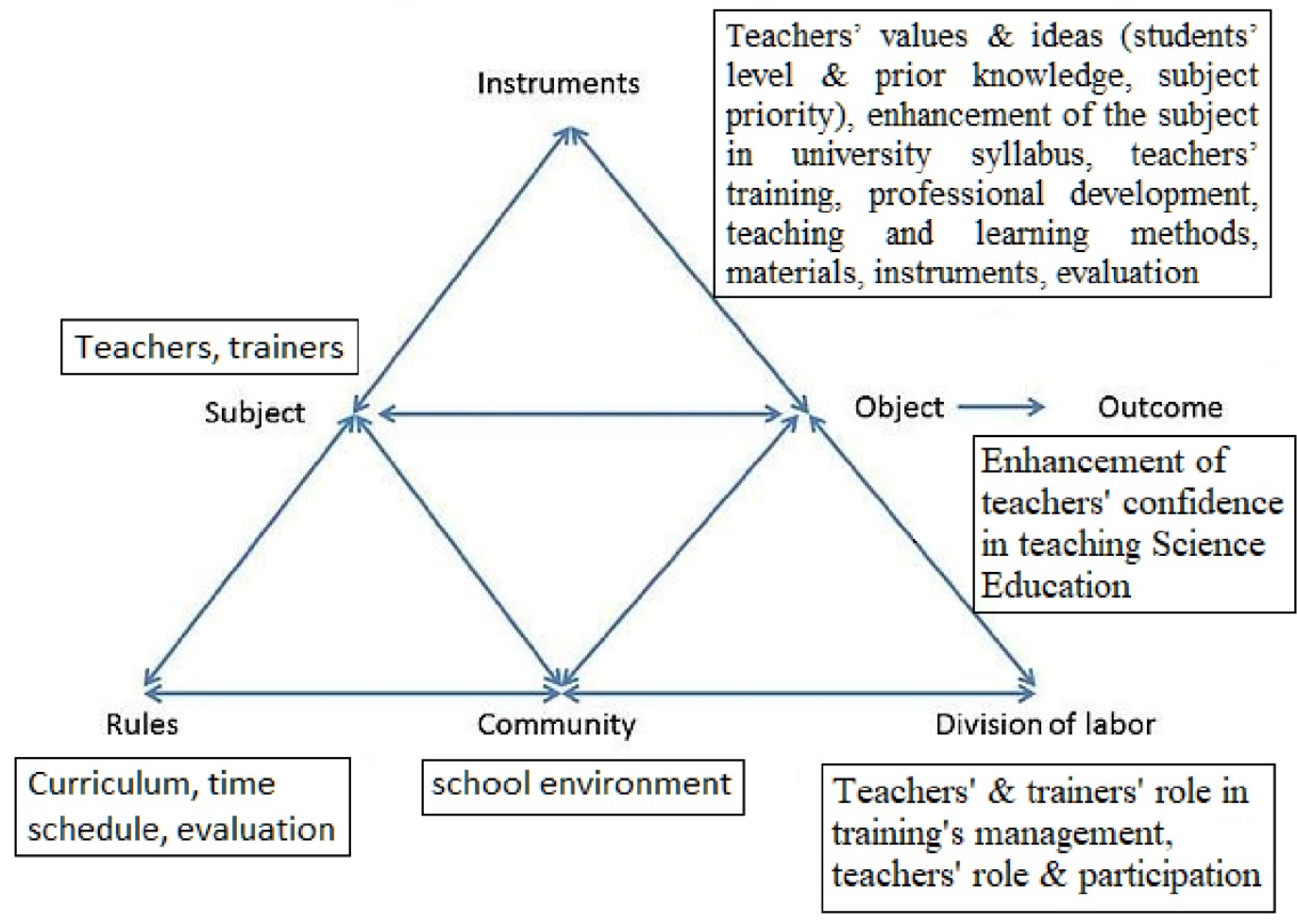

Figure 12. The Current Activity System of Enhancing Teachers' Confidence in Teaching Science

In conclusion, change laboratory methodology is proved according to the present study an effective tool of teachers' training since it can constitute the basis on which meaningful and appropriate training can be designed and implemented during the following steps of the intervention.

\section{Acknowledgement}

This research was financially supported by the Greek State Scholarship Foundation (IKY).

\section{References}

Braund M., \& Reiss M. (2007). Towards a More Authentic Science Curriculum: The contribution of out - of - school learning. International Journal of Science Education. Routledge, 1375 - 1379, 1385 - 1386. 
Engeström, Y. (1987). Learning by expanding: An activity-theoretical approach to developmental research. Helsinki: Orienta-Konsultit.

Engeström, Y. (1996a). Developmental work research as educational research: Looking ten years back and into the zone of proximal development. Nordisk Pedagogik, 16, 131-143.

Engeström, Y. (1999). Activity theory and individual and social transformation. In Y. Engeström, R. Miettinen \& R-L. Punamääki (Eds.), Perspectives on Activity Theory. Cambridge: Cambridge University Press. https://doi.org/10.1017/CBO9780511812774.003

Engeström, Y. (2001). Expansive learning at work: Toward an activity theoretical reconceptualisation. Journal of Education and Work, 14, 133-156. https://doi.org/10.1080/13639080020028747

Engeström, Y. (2015). Learning by Expanding: An activity-theoretical approach to developmental research. Second edition. New York: Cambridge University Press.

Engeström, Y., Virkkunen, J., Helle, M., Pihlaja, J., \& Poikela, R. (1996b). The Change laboratory as a tool for transforming work. Lifelong Learning in Europe, 1(2), 10-17.

Fleer, M. (2006). Understanding the dialectical relations between everyday concepts and scientific concepts within play-based programs. Research in Science Education, 39(2), 281-306. https://doi.org/10.1007/s11165-008-9085-x

Fleer, M. (2009). The cultural construction of child development: Creating institutional and cultural intersubjectivity. International Journal of Early Years Education, 14(2), 127-140. https://doi.org/10.1080/09669760600661294

Foot, K., \& Groleau, C. (2011). Contradictions, transitions, and materiality in organizing processes: An activity theory perspective. First Monday, 16(6), 1-21. https://doi.org/10.5210/fm.v16i6.3479

Kallery, M., \& Psillos, D. (2001). Pre-school Teachers' Content Knowledge in science: Their understanding of elementary science concepts and of issues raised by children's questions. International Journal of Early Years Education, 9(3), 165-179. https://doi.org/10.1080/09669760120086929

Kaptan, K., \& Timurlenk, O. (2012). Challenges for Science Education. Procedia - Social and Behavioral Sciences, 51, 763-771. https://doi.org/10.1016/j.sbspro.2012.08.237

Kuutti, K. (1996). Activity Theory as a potential framework for human computer interaction research. In B. Nardi (Ed.), Context and consciousness: Activity Theory and human computer interaction, pp. 17-44. Cambridge, MA: MIT Press.

Osborne, J., \& Dillion, J. (2008). Science Education in Europe: Critical Reflection. Nuffield Foundation. Retrieved from http://www.nuffieldfoundation.org/science-education-europe

Plakitsi, K. (2012). Sociocognitve and sociocultural approaches in Science Education for early childhood. Athens: Patakis.

Plakitsi, K. (Ed.) (2013). Activity Theory in Formal and Informal Science Education. Series: Cultural perspectives in science education: research dialogs. 252, Rotterdam: Sense Publishers. https://doi.org/10.1007/978-94-6091-317-4

Raikou, N., Karalis, T., \& Ravanis, K. (2017). Implementing an innovative method to develop critical thinking skills is student teachers. Acta Didactica Napocensia, 10(2), 21-30. https://doi.org/10.24193/adn.10.2.2

Ravanis, K. (2017). Early Childhood Science Education: state of the art and perspectives. Journal of Baltic Science Education, 16(3), 284-288.

Ravanis, K., Koliopoulos, D., \& Boilevin, J.M. (2008). Construction of a precursor model for the concept of rolling friction in the thought of preschool age children: a socio-cognitive teaching intervention. Research in Science Education, 38, 421-434. https://doi.org/10.1007/s11165-007-9056-7

Roth, W.-M. (2004). Activity theory and education: An introduction. Mind, Culture and Activity, 11, 1-8. https://doi.org/10.1207/s15327884mca1101_1

Roth, W.M., Goulart, M.I.M., \& Plakitsi, K. (2013). Science Education during Early Childhood. A Cultural Historical Perspective. Dordtrecht: Springer. https://doi.org/10.1007/978-94-007-5186-6

Sannino, A. (2008). From talk to action: Experiencing interlocution in developmental interventions. Mind, culture and activity, 15, 234-257. https://doi.org/10.1080/10749030802186769 
Tu, Y. (2006). Preschool science environment: What is available in a preschool classroom? Early Childhood Education Journal, 33, 245-251. https://doi.org/10.1007/s10643-005-0049-8

Virkkunen, J., \& Newnham, D.S. (2013). The Change Laboratory: A tool for collaborative development of work and education. Rotterdam: Sense Publishers. https://doi.org/10.1007/978-94-6209-326-3

Watters, J. J., Diezmann, C. M., Grieshaber, S. J., \& Davis, J. M. (2001). Enhancing education for young children: A contemporary initiative. Australian Journal of Early Childhood, 26(2), 1-7.

Yilmaz-tuzun, O. (2008). Pre-service Elementary Teachers' Beliefs About Science Teaching. Journal of Science Teacher Education, 19(2), 183-204. https://doi.org/10.1007/s10972-007-9084-1 